\title{
Ameliorative Effect of Young Leaves of Triticum Aestivum on Carrageenin Induced Inflammation
}

\author{
Gaurav Jain*1, Neha Jain ${ }^{2}$, Ameeta Argal ${ }^{1}$ \\ ${ }^{1}$ (Department of Pharmaceutical Sciences, Bhagwant University, Ajmer, Rajasthan, India) \\ ${ }^{2}$ (School of Pharmacy and Research, Peoples University, Bhopal, M.P., India.)
}

\begin{abstract}
Young leaves of Triticum aestivum is commonly known as Wheatgrass and has been widely used in the traditional system for the treatment of a variety of diseases. In this study we have used ninth day wheat grass methanolic extract of the shade dried drug for its anti-inflammatory \& analgesic activities. . It was carried out using Carrageenan induced paw edema volume, Hot plate and Writhing response model which is comparable with standard drug. The methanolic fraction of the grass extract of Triticum aestivum $(500 \mathrm{mg} / \mathrm{kg})$ showed the significant inhibition of carrageenin induced rat paw oedema at the end of fourth hour. The extract also significantly reduced thermal and chemical induced nociception (Hot plate and writhing response) in mice when compared with vehicle treated group. The results prove that the methanolic fraction of the grass extract of Triticum aestivum showed anti-inflammatory activity and analgesic activity in acute inflammation and also proved the usage of traditional claims.
\end{abstract}

Keywords: Analgesic, Anti-Inflammatory, Anti-Nociceptive, Triticum Aestivum

\section{Introduction}

Triticum aestivum grass has been promoted for years for its anti aging and health benefits and is commonly known as 'Wheatgrass' which is essentially a young wheat plant that can be served, juiced or made into a powder. Wheat grass has been used to cure many diseases, it reduces skin toxicity from radiotherapy and has been used to treat various kinds of skin lesions, burns and ulcers, where it acts as a wound healing agent, stimulating granulation tissue and epithelialization.[1,2] Wheatgrass is rich in chlorophyll which consists of chlorophyllin (derivatives of chlorophyll) and has bacteriostatic properties that aids in wound healing.[3] It is reported that rate of healing with chlorophyll is so rapid that its inclusion in armamentarium of burn treatment is suggested because it completely supersedes sulphonamide compounds as primary dressing for clean and potentially infected wounds.[4,5] Its juice also appeared safe and effective as a treatment for ulcerative colitis, an inflammatory condition of the colon. [6] Chernomorsky \& Segelman reported chlorophyllin for its antiinflammatory, wound healing and odor reducing capabilities. Chris Reynolds, an Australian practitioner, has also reported success with acne, alopecia, anal fissure, crohn's disease, eczema, hematoma (bruising), molluscum contagiosum, multiple sclerosis, skin and skin related conditions, sports and soft tissue injuries.[712] Clinically it has been used for osteomyelitis, deep suppurative or draining wounds, diabetic ulcers, vincent's stomatitis and pyorrhea. It hastens skin grafting, cures chronic sinusitis, overcomes chronic inner ear inflammation and infection, reduces varicose veins and heals leg ulcers, eliminates impetigo and other scabby eruptions, heals rectal sores, successfully treat inflammation of the uterine cervix, gets rid of parasitic vaginal infections, reduces typhoid fever, and cures advanced pyorrhea in many cases.[13] Therefore these investigations made it indispensable to evaluate Wheatgrass extract for its efficacy as an anti-inflammatory agent and also for its use as analgesics. In the current study ninth day wheatgrass is used since the age of the plant matters a lot in its potency.

\section{Materials and Methods}

\subsection{Procurement and authentication of the plant material}

The Wheatgrass seeds for the research were purchased from Breeder Seed Production Unit Field crops, Department of Plant Breeding and Genetics, Jawahar Lal Nehru Krishi Vishwavidyalaya, Krishinagar, Jabalpur M.P. and the release order number was obtained. The whole plant of Triticum aestivum was collected in the month of December and authenticated at Safia college of Science Bhopal, Madhya Pradesh. The herbarium of the plant was prepared and the voucher specimen number 236/BOT/SAFIA/2011 was obtained.

\subsection{Preparation of Triticum aestivum powder.}

The grass of Triticum aestivum was cultivated till ninth day and chopped with the help of knife. It was dried in shade and then powdered with a mechanical grinder. The powder was passed through sieve no.40 and stored in a labeled air tight container for further studies. 


\subsection{Preparation of Extract}

Maceration process involves separation of medicinally active portions of the crude drugs. It is based on the immersion of the crude drugs in the bulk of solvent or menstrum. Solid drug material was taken in a stopperd container with about $750 \mathrm{ml}$ of the menstrum and allowed to stand for at least three to seven days in a warm place with frequent shaking. The mixture of crude drug containing solvent was filtered until most of the liquid drains off. The filtered and the washing were the combined to produce $1000 \mathrm{ml}$ of the solution. This solution was kept aside for solidification and after it was dried on hot air oven for $30 \mathrm{~min}$ at $40^{\circ} \mathrm{C}$. The extract was then collected in a dry dark color bottle.[14]

\subsection{Anti-nociceptive activity}

Pain is a common phenomenon in all animals, at least in vertebral animals, similar to that felt by man. Pain is a symptom of many diseases requiring treatment with analgesics. Analgesic effects in animals are comparable with the therapeutic effects in man. Lim and Guzman (1968) differentiated between antipyretic analgesics and narcotic analgesics. Antipyretic analgesics cause analgesia by blocking impulse generation at pain receptors in the periphery while the narcotic analgesics block synaptic transmission of impulses signaling pain in the central nervous system. We have utilized two different models of pain to distinguish between analgesic activities of Triticum astivum grass extract, whether central or peripheral.

\subsubsection{Tail-flick test in mice}

Analgesic activity was measured by the tail flick method, using the Analgesiometer (INCO Lab. Ambala) as described by Armour and Smith. For each animal, the tail flick latency was obtained thrice before drug administration, and mean was used as pre-drug latency. The tail flick latencies were measured at $0,0.5,1$, 2 and $3 \mathrm{~h}$ after administration $(500 \mathrm{mg} / \mathrm{kg}$ p.o.) of Triticum aestivum extract.[15,16] The animals of control group received vehicle $(0.5 \% \mathrm{CMC})$ and standard group received Pentazocine $(3.9 \mathrm{mg} / \mathrm{kg}$ mice i.p.) for animals that did not respond within the cut-off time of 10 seconds, the value of the cut-off time was considered as latency period for that animal to avoid injury to tail.

\subsubsection{Acetic acid-induced writhing test in mice}

Pain is induced by injection of irritants into the peritoneal cavity of mice. The animals react with a characteristic stretching behavior which is called writhing. An irritating agent such as phenylquinone or acetic acid is injected i.p. to mice and the stretching reaction is evaluated.

Mice of either sex with a weight between 20-25 g were used. Groups of 6 animals were used for control and treatment. Test animals were administered the extract $(500 \mathrm{mg} / \mathrm{kg}$ p.o.) and the standard (Indomethacin-5mg/kg i.p.). $30 \mathrm{~min}$ after treatment, the mice were given an intraperitoneal injection of $0.6 \% \mathrm{v} / \mathrm{v}$ acetic acid in a volume of $10 \mathrm{ml} / \mathrm{kg}$ to induce the characteristic writhing. The mice were then observed for a period of $15 \mathrm{~min}$ and the number of writhes (stretching episode of belly and touching on the floor when moving) occurring between 5 and 15 min after acetic acid injection was recorded for each animal. The percent inhibition was calculated by using following formula. The time period with the greatest percentage of inhibition is considered as peak time.[15,17]

: Percent Inhibition $=$ AWc-AWt/AWc $\times 100$

$\mathrm{AWc}=$ Average writhes in the control

$\mathrm{AWt}=$ Average writhes in the treated group

\subsection{Anti-inflammatory Activity}

\subsubsection{Carrageenan induced paw edema in rats}

Among the many methods used for screening of anti-inflammatory drugs, one of the most commonly employed technique is based upon the ability of such agents to inhibit the edema produced in the hind paw of the rat after injection of a phlogistic agent.

Young healthy and adult Wistar rats of both sexes average body weight 150-200 g were used. The animals were starved overnight. Twelve groups of six rats were allotted to different treatment groups. Group I (control) was treated with vehicle to insure uniform hydration. Test group was treated orally with two doses $(500 \mathrm{mg} / \mathrm{kg})$ of extract and other group was treated with $10 \mathrm{mg} / \mathrm{kg}$ p.o.indomethacin used as reference.[18,19] 30 min later, the rats were challenged by a subcutaneous injection of $0.1 \mathrm{ml}$ of $1 \%$ solution of Carrageenan (Sigma chemicals Co.) into the plantar side of the left hind paw. The paw was marked with ink at the level of the lateral malleolus and immersed up to this mark. The paw volume was measured with the help of Digital Paw edema meter (520-R, IITC Life Science, USA) immediately after injection, again after 1, 2, 3 and $4 \mathrm{~h}$ intervals of carrageenan administration. 


\subsection{Anti-Nociceptive Activity}

\section{Results and Discussion}

\subsubsection{Tail-flick test in mice}

Tail flick latency was studied for Triticum aestivum extract and compared with control group. After 3 hours of study extract has shown significant $(* * \mathrm{P}<0.01)$ anti-nociceptive activity. It is clearly shown in the table that the latency period is gradually increasing with the time when compared to control on early and late phases nociception. Results are shown in Table and Fig. given below.

Table: Anti-nociceptive activity of Triticum aestivum extract on mice by using Tail flick method

\begin{tabular}{|c||c||c||c||c|c||}
\hline \hline \multirow{3}{*}{ Treatment } & \multicolumn{5}{|c|}{ Tail withdrawing time (Sec.) } \\
\cline { 2 - 6 } & $\mathbf{0 ~ h r . ~}$ & $\mathbf{0 . 5}$ hr. & $\mathbf{1 ~ h r .}$ & $\mathbf{2 ~ h r .}$ & $\mathbf{3 ~ h r .}$ \\
\hline \hline Control & $2.16 \pm 0.16$ & $2.18 \pm 0.12$ & $2.23 \pm 0.21$ & $2.36 \pm 0.04$ & $2.32 \pm 0.05$ \\
\hline \hline Pentazocine & $2.16 \pm 0.16$ & $3.5 \pm 0.02^{* *}$ & $5.33 \pm 0.01^{* *}$ & $7.16 \pm 0.18^{* *}$ & $7.83 \pm 0.08^{* *}$ \\
\hline \hline Extract & $2.16 \pm 0.07$ & $3.33 \pm 0.21^{*}$ & $4.13 \pm 0.01^{*}$ & $5.43 \pm 0.01^{* *}$ & $6.18 \pm 0.08^{* *}$ \\
\hline
\end{tabular}

Values are expressed as mean \pm SEM $(\mathrm{N}=6), * \mathrm{P}<0.05$, $* * \mathrm{P}<0.01$ compared with vehicle control (ANOVA followed by Dunnett's t-test).

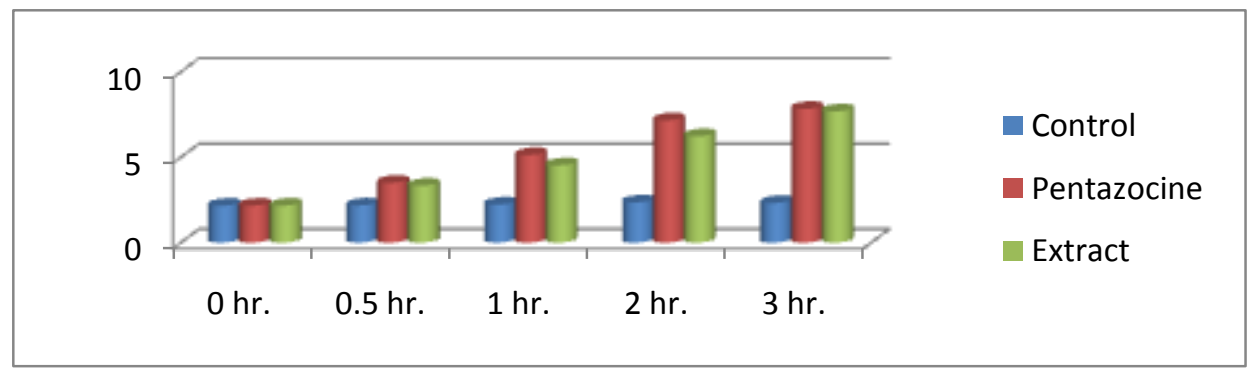

\section{Graph: Anti-nociceptive activity of Triticum aestivum extract by using tail flick method}

\subsubsection{Acetic acid induced writhing test in mice}

Acetic acid induced writhing is a visceral pain model, which is widely used for the evaluation of general analgesic activity. In this model, pain is generated indirectly via endogenous mediators like bradykinin, serotonin, histamine, substance $\mathrm{P}$, and prostaglandins, acting on stimulating peripheral nociceptive neurons, which are sensitive to narcotic analgesics and non-steroid anti-inflammatory drugs (NSAIDs). In the writhing test, number of writhing was recorded against acetic acid induced writhing, from the results it is clear that the extract produced decrease in the number of writhing in comparison with the control group $\left({ }^{*} \mathrm{P}<0.01\right)$, extract suppressed acetic acid induced writhing and are shown in table and Fig. given below.

Table: Anti-nociceptive activity of Triticum aestivum extract on mice by using Acetic acid-induced writhing test

\begin{tabular}{|c||c||}
\hline Treatment & $\begin{array}{c}\text { Number of writhing } \\
(\text { Mean } \pm \text { SEM) }\end{array}$ \\
\hline \hline Control & $43.74 \pm 0.71$ \\
\hline \hline Indomethacin & $22.41 \pm 0.13^{*}$ \\
\hline \hline Extract & $32.25 \pm 0.20^{*}$ \\
\hline
\end{tabular}

Values are expressed as mean \pm SEM $(\mathrm{N}=6), 500 \mathrm{mg} / \mathrm{kgp} .0$, Indomethacin-5mg $/ \mathrm{kg}$ i.p, ${ }^{*} \mathrm{P}<0.01$ compared with vehicle control (ANOVA followed by Dunnett's t-test)

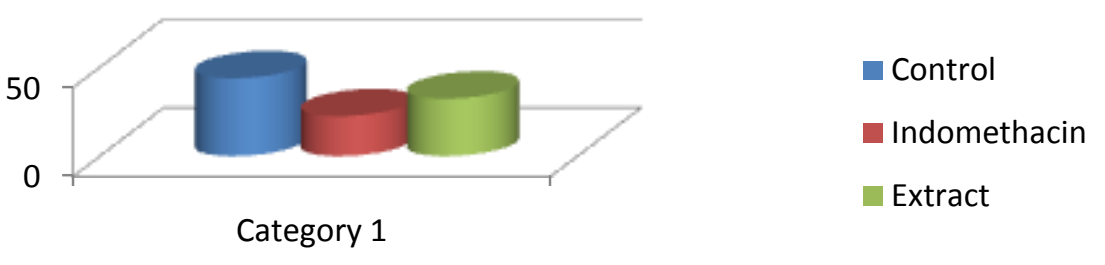

Graph: Anti-nociceptive activity of Triticum aestivum extract on mice by using acetic acid-induced writhing test 


\subsection{Anti-Inflammatory Activity}

3.2.1 Carrageenan-induced paw edema in rats

The carrageenan induced paw edema is a useful tool for the investigation of systemic antiinflammatory agents. This test is sensitive to most clinically effective anti-inflammatory drugs and comprises of two phases. The initial phase, which occurs within 1-2 $\mathrm{h}$ after carrageenan injection, is due to the release of serotonin and the increase of prostaglandin, histamine, and bradykinin in the inflammatory area. The second phase occurs 3-4 h after carrageenan injection which is correlated with production and release of kinins and prostaglandins in the inflammatory area. The extract showed inhibition of the rat paw edema in both phases, results are shown in Table and Fig given below. The extract has shown significant anti-inflammatory activity with $* * \mathrm{P}<0.01$ when compared with vehicle control after four hour study.

Table: Anti-inflammatory activity of Triticum aestivum extract against Carrageenan induced acute paw edema in rats

\begin{tabular}{|c|c|c|c|c|}
\hline \multirow{2}{*}{ Treatment } & \multicolumn{4}{|c|}{ Paw volume (Mean \pm SEM) in $\mathrm{ml}$} \\
\hline & 1hr. & 2hr. & 3hr. & 4hr. \\
\hline Control & $0.98 \pm 0.015$ & $1.27 \pm 0.08$ & $\bar{~} 1.34 \pm 0.01$ & 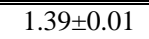 \\
\hline Indomethacin & $0.81 \pm 0.03 * *$ & $0.75 \pm 0.17 * *$ & $0.69 \pm 0.02 * *$ & $0.61 \pm 0.02 * *$ \\
\hline Extract & $0.86 \pm 0.01 *$ & $0.83 \pm 0.024 *$ & $0.78 \pm 0.05^{* *}$ & $0.71 \pm 0.03 * *$ \\
\hline
\end{tabular}

Values are expressed as mean \pm SEM $(\mathrm{N}=6), 500 \mathrm{mg} / \mathrm{kgp} . \mathrm{o}$, Indomethacin $\left(10 \mathrm{mg} / \mathrm{kg}\right.$ p.o.), ${ }^{*} \mathrm{P}<0.05,{ }^{* * \mathrm{P}}<0.01$ compared with vehicle control (ANOVA followed by Dunnett's t-test)

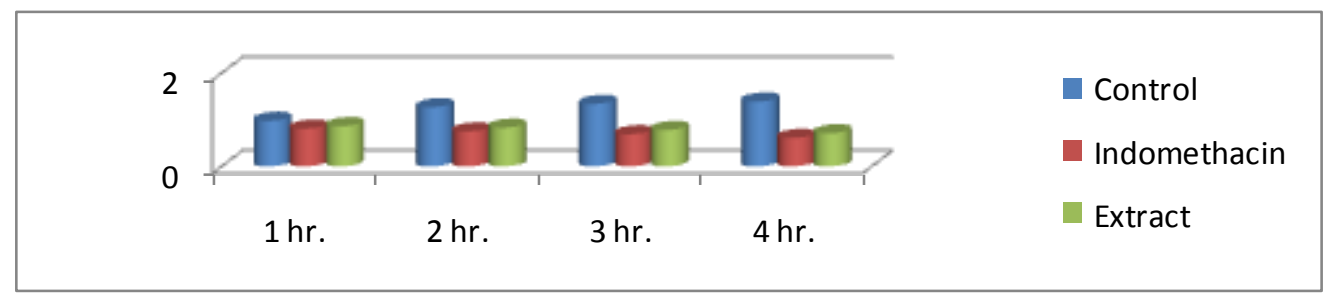

Graph: Anti-inflammatory activity of Triticum aestivum extract against carrageenan induced acute paw edema in rats

\section{Conclusion}

A potent analgesic and anti-inflammatory effects were recorded with Triticum aestivum grass extract. Present investigation suggested that the extract is having both centrally and peripheral analgesic activity. In antiinflammatory activity it inhibits paw edema (inflammation) significantly, which revealed that it may be potent therapeutic agent to treat inflammatory diseases. This preclinical research work provides the outcome of Triticum aestivum grass can be a drug candidate for pain and inflammation. Further investigation is needed to elucidate the exact mechanism behind pharmacological effects and special toxicity studies are needed to assure the safety of the drug.

\section{References}

[1]. G. Balint, A. Apathy, M. Gaal, A. Telekes, A. Resetar, G. Blazso, G. Falkay, B. Szende, A. Paksy, M. Ehrenfeld, Y. Shoenfeld and M. Hidvegi, Effect of Avemara a fermented wheat germ extract on rheumatoid arthritis Preliminary data, Clinical Experimental Rheumatology 24(3), 2006, 325-328.

[2]. MA Young, JL. Cook, KE. Webster, The effect of topical wheatgrass cream on chronic plantar fasciitis: a randomized, doubleblind, placebo-controlled trial, Complement Therapeutics Medicine, 14(1), 2006, 3-9.

[3]. SA. Chernomorsky, AB. Segelman : Biological activities of chlorophyll derivatives, N J Med, 85(8), 1988, 669-73.

[4]. J. Grunewald, Novel Botanical ingredients for beverages, Clinics for Dermatology, 27, 2009, 210-216.

[5]. R. Satyavati, K. Jaspreet Kambojand and G. Vandana, Living life the natural way - Wheatgrass and Health, Functional Foods in Health and Disease, 1(11), 2011, 444-456.

[6]. E. Ben-Arye, E. Goldin, D. Wengrower, A. Stamper, R. Kohn, E. Berry, Wheat grass juice in the treatment of active distal ulceative colitis: a randomized double blind placebo controlled trial, Scand Journal of Gastroenterology, 37(4), 2002, 444-9. http://www.ncbi.nlm.nih.gov/pubmed/11989836.

[7]. http://www.drwheatgrass.com.au/LiteratureRetrieve.aspx?ID=29583. Wound healing? Think growth factors. by Dr. Chris Reynolds. M.B.B.S.

[8]. http://www.drwheatgrass.com.au/conditions/alopecia/case_2 ALOPECIA AREATA CASE

[9]. http://www.drwheatgrass.com/info/newsletters/default.htm Dr. Chris' Wheatgrass.

[10]. http://www.wheatgrassprofessional.info/default.htm Wheatgrass For Inflammation Chris Reynolds. 
[11]. http://www.tonicattack.com/documents/Wheatgrass_for_Crohns_and_IBS.pdf Wheatgrass and IBS/Crohns disease - by Dr. Chris Reynolds M.B.,B.S April, 2004 - Crohn's Disease \& The Return of Wheatgrass Healing Crohn's Disease.

[12]. http://ezinearticles.com/?Wheatgrass-For-Anal-Fissure---A-Medical Breakthrough\&id=118762 Wheatgrass For Anal Fissure - A Medical Breakthrough By Dr. Chris Reynolds.

[13]. http://www.time.com/time/magazine/article/0,9171,764228,00.html.Chlorophyll for Colds Monday, Jul. 22, 1940 Professor Benjamin Gruskin of Philadelphia's Temple University.

[14]. P.K. Mukherjee, Quality control of herbal drugs (1 ${ }^{\text {st Ed. }) ~ B u i s n e s s ~ H o r i z o n s-N e w ~ D e l h i ~ 2010) ~ 186-189 . ~}$

[15]. GH. Vogal, Pharmacological Assay ( $1^{\text {st }}$ Ed.) Drug Discovery and Evaluation, 1 (Berlin: Springer, 2002) 755-756

[16]. M. Mahmoudi, K. Morteza Semnani, E. Mojra, Anti-inflammatory and Antinociceptive activity of Thymus pubescens extract, Fitoterapia, 79, 2008, 361-365.

[17]. A. Bose, S. Mondal, JK. Gupta, T. Ghosh, GK. Das, S. Singh, Analgesic, Anti-inflammatory and Antipyretic activities of the ethanolic extract and its fraction of Cleome rutidosperma, Fitoterapia, 78, 2007, 515-520.

[18]. H. Joshi, AJ. Joshi, MP. Gururaj, K. Chandrashekar, EVS. Subramanyam and D. Satyanarayana, Anti-inflammatory potential of Memecylon Umbellatum root extract, International Journal of Pharmacology Biology Scences, 3(1), 2009, 11-15.

[19]. CA.Winter, GW. Risely, Carrageenan induced edema in hind paw of the rat as an assay for anti-inflammatory drug, Proceedings of Society Experimental Biology Med, 111, 1963, 544. 